\title{
Efficient Genome Editing of a Facultative Thermophile Using Mesophilic spCas9
}

\author{
Ioannis Mougiakos, ${ }^{\dagger, \S}$ Elleke F. Bosma, ${ }^{\dagger, \S, \|}$ Koen Weenink, ${ }^{\dagger}$ Eric Vossen, ${ }^{\dagger}$ Kirsten Goijvaerts, ${ }^{\dagger}$ \\ John van der Oost, ${ }^{\dagger}$ and Richard van Kranenburg*, ${ }^{*}, \ddagger 0$ \\ ${ }^{\dagger}$ Laboratory of Microbiology, Wageningen University, Stippeneng 4, 6708 WE Wageningen, The Netherlands \\ ${ }^{\ddagger}$ Corbion, Arkelsedijk 46, 4206 AC Gorinchem, The Netherlands
}

\section{Supporting Information}

ABSTRACT: Well-developed genetic tools for thermophilic microorganisms are scarce, despite their industrial and scientific relevance. Whereas highly efficient CRISPR/Cas9-based genome editing is on the rise in prokaryotes, it has never been employed in a thermophile. Here, we apply Streptococcus pyogenes Cas9 (spCas9)-based genome editing to a moderate thermophile, i.e., Bacillus smithii, including a gene deletion, gene knockout via insertion of premature stop codons, and gene insertion. We show that spCas9 is inactive in vivo above $42{ }^{\circ} \mathrm{C}$, and we employ the wide temperature growth range of $B$. smithii as an induction system for spCas9 expression. Homologous recombination with plasmid-borne editing templates is performed at 45$55{ }^{\circ} \mathrm{C}$, when spCas9 is inactive. Subsequent transfer to $37{ }^{\circ} \mathrm{C}$ allows for counterselection through production of active spCas9, which introduces lethal double-stranded DNA breaks to the nonedited cells. The developed

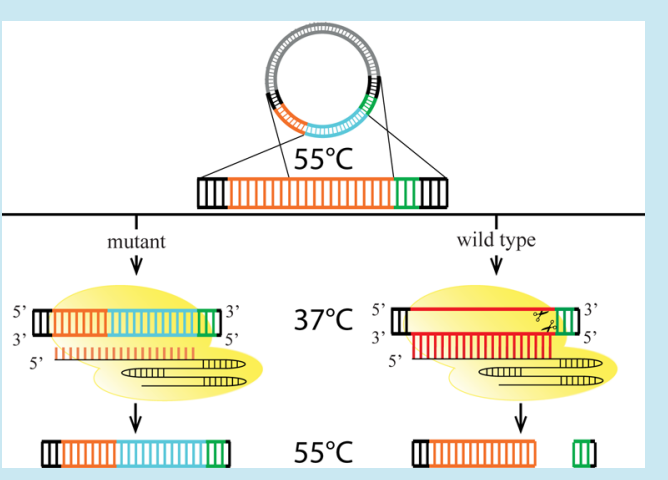
method takes 4 days with 90, 100, and $20 \%$ efficiencies for gene deletion, knockout, and insertion, respectively. The major advantage of our system is the limited requirement for genetic parts: only one plasmid, one selectable marker, and a promoter are needed, and the promoter does not need to be inducible or well-characterized. Hence, it can be easily applied for genome editing purposes in both mesophilic and thermophilic nonmodel organisms with a limited genetic toolbox and ability to grow at, or tolerate, temperatures of 37 and at or above $42{ }^{\circ} \mathrm{C}$.

KEYWORDS: CRISPR/Cas9, bacteria, Bacillus smithii, thermophiles, genome editing, homologous recombination

$\mathrm{M}$ crobial fermentation of renewable resources into green fuels and chemicals is playing a major part in the development of the biobased economy. The production costs of these environmentally friendly processes have to be reduced before they become competitive with traditional fossil fuelbased industries. To this end, microbes other than the widely used model organisms, such as Escherichia coli and Saccharomyces cerevisiae, are being evaluated for their prospective abilities to act as production hosts. Thermophilic organisms are of particular interest due to their multiple advantages over mesophilic organisms when being used as production hosts. ${ }^{1-3}$ For example, their ability to grow and ferment at thermophilic temperatures reduces the cooling costs, ${ }^{4,5}$ and increase substrate and product solubility, ${ }^{6}$ it reduces the contamination risk with mesophiles, ${ }^{7-9}$ and there are examples of using thermophiles for nonsterilized fermentations which would reduce sterilization costs, ${ }^{10,11}$ additionally, the fermentation process runs at the optimum temperature for enzymatic lignocellulose degradation, allowing for efficient simultaneous saccharification and fermentation. ${ }^{12,13}$ However, the use of nonmodel thermophiles as production hosts is generally hampered by the lack of well-developed genome editing tools compared to those available for currently used mesophilic model organisms. 1,14
Previous work has established basic genome editing tools for the facultative thermophilic strain Bacillus smithii ET 138 (referred to as ET 138 herein), allowing for the introduction of scar-free markerless gene deletions using homologous recombination. ${ }^{15}$ B. smithii grows between 37 and $65{ }^{\circ} \mathrm{C}$ and efficiently utilizes both $\mathrm{C}_{5}$ and $\mathrm{C}_{6}$ sugars. ${ }^{16,17}$ Its main product is L-lactate, and in order to use ET 138 as a versatile platform host for the production of other chemicals and fuels, its $l d h L$ gene was deleted. No counterselection tool was used in this process, resulting in a very laborious screening process to obtain clean mutants. ${ }^{15}$ Subsequently, a lacZ-based counterselection was developed that relies on the toxicity of high concentrations of 5-bromo-4-chloro-3-indolyl- $\beta$-D-galactopyranoside (X-gal). ${ }^{15,18}$ Using this system, the sporulation gene sigF and the pyruvate dehydrogenase complex subunit gene $p d h A$ were consecutively deleted in the $l d h L$ mutant. The resulting triple mutant strain was sporulation-deficient, which is desired in industrial fermentations for safety reasons, and did not produce L-lactate and acetate. Since the $p d h A$ mutant was also acetate auxotrophic, the double mutant ET $138 \Delta l d h L \Delta s i g F$ was

Received: November 9, 2016

Published: February 1, 2017 
selected as a basic platform strain for future studies. ${ }^{15}$ Although the lacZ-based counterselection system significantly decreased the time needed for mutant selection, the developed process is still time-consuming, with the fastest possible route to gene deletion taking approximately 2 to 3 weeks from transformation to generation of a scar-free markerless knockout. ${ }^{15}$ Moreover, the counterselection step is not stringent enough for removal of genes that are essential for the fitness and the metabolism of the strain. For the successfully engineered genes, only 12.5$33 \%$ of the colonies had the mutant genotype, whereas for other genes, only wild-type revertants and false positives were obtained, generating mostly $(66-88 \%)$ or in some cases only wild-type revertants or false positives. ${ }^{15}$ The large number of wild-type revertants due to the absence or inefficiency of counterselection is a general issue in several nonmodel organisms. ${ }^{19,20}$ This creates the need for laborious PCR-based screening and strongly decreases throughput of the engineering process, limiting the study of these organisms and their development into industrial production hosts.

One of the fastest and most efficient methods currently available for genome editing is a system based on the Streptococcus pyogenes Cas9 (spCas9) RNA-guided DNA endonuclease of the type II CRISPR-Cas defense system. ${ }^{21}$ Jinek et al. showed that a short single guide RNA (sgRNA) molecule can direct the spCas9 endonuclease to a desired complementary target, called protospacer. ${ }^{22}$ In the presence of the short 5'-NGG-3' DNA motif immediately downstream of the $3^{\prime}$-end of the protospacer, called protospacer adjacent motif (PAM), spCas9 introduces a lethal chromosomal double stranded DNA break (DSDB). ${ }^{22}$ The system was applied for genome editing of human ${ }^{23-26}$ and mouse cells, ${ }^{25}$ paving the road for genome editing of a wide range of eukaryotic cells. $^{27-29}$ In these eukaryotes, the non-homologous end joining (NHEJ) system repairs spCas9-induced DSDBs in an error-prone manner, creating insertion/deletion (indel) mutations. $^{23-26}$ These mutations usually render the gene inactive through frameshifting and simultaneously prevent further spCas9 recognition and subsequent cleavage due to the alteration of the target site. Although the NHEJ system is generally not present or not active for most prokaryotes, ${ }^{30}$ the ET 138 genome contains the genes for the basic prokaryotic NHEJ-like system, consisting of DNA ligase LigD and DNAend-binding protein $\mathrm{Ku} .{ }^{31,32}$ However, the functionality of the NHEJ-like system in ET 138 is unknown.

The combination of spCas9 activity with editing templates, such as recombineering oligonucleotides or plasmid-borne sequences for homologous recombination, has been recently exploited for prokaryotic genome editing. ${ }^{33-35}$ spCas9 was employed to introduce DSDBs in prokaryotic genomes. These breaks modestly induced the recombination of a provided rescuing/editing template into the targeted chromosome, resulting in genetically modified cells. ${ }^{33,36,37}$ The edited cells avoided subsequent spCas 9 targeting events, but in many studies, the number of surviving/edited colonies was low, with a high percentage of mixed (both wild type and mutant) or escape mutant genotypes. ${ }^{38-40}$ The number of surviving colonies as well as the percentage of successfully edited cells was higher in studies that allowed homologous recombination of the editing templates to take place prior to spCas9 targeting. In this way, spCas9 was employed for stringent counterselection of unedited genomes. For this approach, either homologous recombination was faster than spCas9 targeting or cas $9_{\text {sp }}$ expression was induced after homologous recombina- tion. ${ }^{41-43}$ Moreover, the vast majority of studies required either a multiple-plasmid system or very tightly controlled promoters. ${ }^{42,44}$ Currently, only one plasmid, one selection marker, and no inducible promoters are available for ET 138, limiting the options for such systems. Many of the well-known and widely applied genome editing tools, including CRISPR-Cas9 editing, are not amenable to thermophiles. The enzymatic machineries of these tools have not proven to be stable at temperatures higher than $37^{\circ} \mathrm{C}$. Whereas the native CRISPRCas type I system of a thermophilic archaeon has been employed for genome editing ${ }^{45}$ and chromosome-based genetic manipulations have been reported for a few naturally competent thermophiles, ${ }^{46}$ no reports are available on using Cas9-based editing in thermophilic organisms.

In this study, we show that spCas9 is inactive in ET 138 at temperatures from $42{ }^{\circ} \mathrm{C}$ and above and we tightly control its activity by altering the cultivation temperature rather than by using an inducible promoter. We create a clean gene deletion, a gene disruption, and a gene insertion by employing a plasmidborne homologous recombination template for introduction of the desired modifications to the genome at $45{ }^{\circ} \mathrm{C}$, and the nonedited cells are subsequently eliminated by spCas 9 counterselection at $37{ }^{\circ} \mathrm{C}$. To the best of our knowledge, this is the first time that a temperature-controlled recombination/ counterselection tool has been employed for genome editing purposes, and it is the first time that a Cas9-based editing tool has been used for engineering the genome and the metabolism of a moderate thermophile.

\section{RESULTS AND DISCUSSION}

In Vivo Expression Validation of spCas9 at Different Temperatures. In a parallel study, we demonstrated that the in vitro sgRNA loading to spCas9 requires temperatures below $42{ }^{\circ} \mathrm{C}$, which is the limiting step toward the in vitro formation of the active sgRNA-spCas 9 complex (to be published). This result motivated us to evaluate the in vivo activity of spCas9 in ET 138 at different temperatures. We designed and constructed the modular pWUR_Cas9nt construct, which encompasses the cas 9 gene of $S$. pyogenes (referred to as cas $9_{s p}$ herein) and an sgRNA-expressing module for which the spacer is predicted not to target any site of the B. smithii genome (i.e., nt, for nontargeting). The backbone of pWUR Cas9nt is the pNW33n vector, which was the only available vector for $B$. smithii (Figure 1A). ${ }^{15,16}$ The first basic requirement for the design of the pWUR_Cas9nt was the development of promoters that will drive the expression of the two components of the system: the cas $9_{s p}$ effector and its sgRNA guide module. For many nonmodel organisms, the number of available promoters and plasmids is very limited. ET 138 is no exception; only two promoters have been evaluated for expression in $B$. smithii: the heterologous $\mathrm{P}_{p t a}$ from $B$. coagulans and the native $\mathrm{P}_{\text {ldhL }} \cdot{ }^{15}$ The latter is undesired, as integration of pNW33n-based HR plasmids into the ET 138 genome is possible ${ }^{15}$ and we want to prevent crossover events between the pWUR Cas9nt construct and the B. smithii genome over the promoter region. Additionally, an inducible system would be desirable. For these purposes, we tested the xynA promoter $\left(\mathrm{P}_{x y n A}\right)$ from Thermoanaerobacterium saccharolyticum. ${ }^{47}$ In the genome of its native host, this promoter is induced by xylose and repressed by glucose. To test expression in ET 138, we constructed the pWUR lacZ vector; we used pNW33n as the cloning and expression vector, and we introduced $\mathrm{P}_{x y n A}$ in front of the $B$. coagulans-derived lac $Z$ gene, previously shown to be functional 

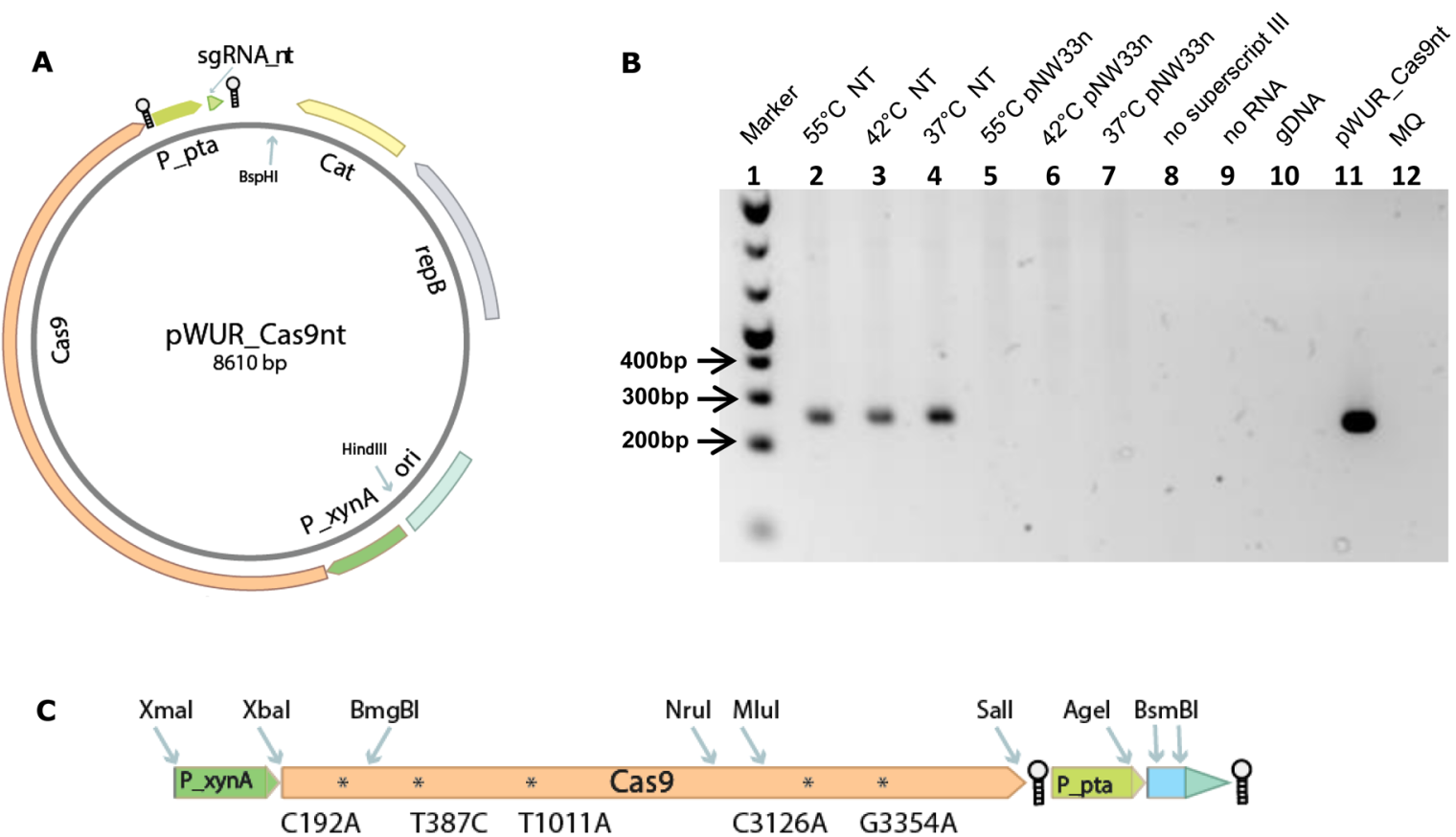

Figure 1. Schematic overview of the basic pWUR_Cas9nt construct. (A) The non-codon-optimized cas $9_{s p}$ gene was employed for the construction of the pWUR_Cas9nt vector, since S. pyogenes and B. smithii GC content and codon usage are highly similar. In the pNW33n-based basic construct, $s p$ Cas 9 was placed under the control of $\mathrm{P}_{x y n A}$. A Rho-independent terminator from B. subtilis ${ }^{59}$ was introduced after the stop codon of the gene. The spCas 9 module is followed by an sgRNA-expressing module that encompasses a spacer which does not target the genome of ET 138. The sgRNA module was placed under the transcriptional control of $\mathrm{P}_{\text {pta }}$ from B. coagulans (without its RBS), which was followed by a second Rho-independent terminator from B. subtilis. ${ }^{15,49}$ The spCas9 and sgRNA modules were synthesized as one fragment, which was subsequently cloned into pNW33n through the BspHI and HindIII restriction sites. (B) To prevent double restriction sites and create a modular system, five silent point mutations (C192A, T387C, T1011A, C3126A, G354A) were introduced to the gene (depicted as *). The depicted restriction sites are unique in the construct and introduced to facilitate the exchange of genetic parts. The spacer was easily exchanged to targeting spacers via BsmBI restriction digestion or Gibson assembly. The basic construct did not contain any HR templates, but in cases where these were added, they were always inserted immediately upstream of the spCas9 module and downstream of the origin of replication. (C) Total RNA was isolated from ET 138 wild-type cells transformed with pWUR_Cas9nt or pNW33n and grown at 55, 45, and $37^{\circ} \mathrm{C}$. Six cDNA libraries were produced with rt-PCR and used as templates for PCR with cas9sp-specific primers that amplify a $255 \mathrm{bp}$ region. The PCR results are depicted as follows: lane 1 corresponds to the marker (1kb+ DNA ladder, ThermoFisher), lanes 2-4 correspond to ET 138 wild-type cultures transformed with pWUR_Cas9nt and grown at 55, 42 , or $37{ }^{\circ} \mathrm{C}$, respectively, lanes 5-7 correspond to ET 138 wild-type cultures transformed with pNW33n and grown at 55,42 , or $37^{\circ} \mathrm{C}$, respectively, lanes $7,8,9$, 11, 12 correspond to different negative controls, and lane 10 corresponds to the positive control, for which pWUR_Cas9nt was used as the PCR template.

in ET $138 .{ }^{15}$ Low expression was observed after overnight culture in LB2 liquid medium without an added carbon source, and strong expression was observed with both xylose and glucose (Figure S1). It is probable that the catabolite repression mechanism of ET 138 does not recognize the cre (catabolite repression element) sequence present on $\mathrm{P}_{x y n A}$, resulting in lack of transcriptional repression by glucose in B. smithii ET 138 . Although $\mathrm{P}_{x y n A}$ is not tightly controllable in B. smithii, we still selected it to drive the expression of cas9 from pWUR Cas9nt, maintaining the possibility to explore the effects of different cas $9_{s p}$ expression levels. During all further experiments in this study, xylose and glucose were both added to the media at all of the culturing temperatures to ensure constant induction of cas $9_{s p}$ expression at all times from $\mathrm{P}_{x y n A}$. Additionally, we placed the sgRNA module under the control of the $B$. coagulans phosphotransacetylase ( $p t a$ ) promoter $\mathrm{P}_{p t a}^{15,49}$ without its RBS. It is generally stressed that the transcriptional start site (TSS) of the promoter driving sgRNA expression must be characterized. However, the TSS of $\mathrm{P}_{\text {pta }}$ that we use for the same purpose in our study is not characterized, and since we remove only the predicted RBS, we expect that a few nucleotides are still added to the $5^{\prime}$-end of the sgRNA molecules. Even so, we hypothesized that this extended sgRNA module will be efficiently loaded to spCas9 and that it will not influence the Cas9 targeting efficiency and specificity, since it is located at the PAM distal end. By verifying our hypothesis, we would facilitate the application of our system to other nonmodel organisms with promoters that do not have their TSS determined.

We evaluated spCas9 expression and toxicity levels in ET 138 by transforming a single batch of competent cells with the nontargeting pWUR Cas9nt vector and with the empty pNW33n control vector. The transformed cells were plated on LB2 plates supplemented with chloramphenicol. We incubated the plates overnight only at $55^{\circ} \mathrm{C}$, as previous incubation attempts at 37 and $42{ }^{\circ} \mathrm{C}$ were not successful (data not shown). One colony per transformation was used for sequential transfers in $\mathrm{LB} 2_{\mathrm{xg}}$ broth, transferring the cultures from 55 to $37^{\circ} \mathrm{C}$, with two intermediate steps at 45 and $42{ }^{\circ} \mathrm{C}$. We isolated total RNA from each pWUR Cas9nt culture after $18 \mathrm{~h}$ of incubation at 55,42, and $37^{\circ} \mathrm{C}$ and performed semiquantitative reverse transcription (rt)-PCR using specific primers for the $\operatorname{cas} 9_{s p}$ gene. Transcription of $c a s 9_{s p}$ was observed for all tested temperatures (Figure 1B). The growth of the cas $9_{s p}$-expressing cultures was similar to that of the pNW33n control cultures at all temperatures (Figure 2B), indicating that 

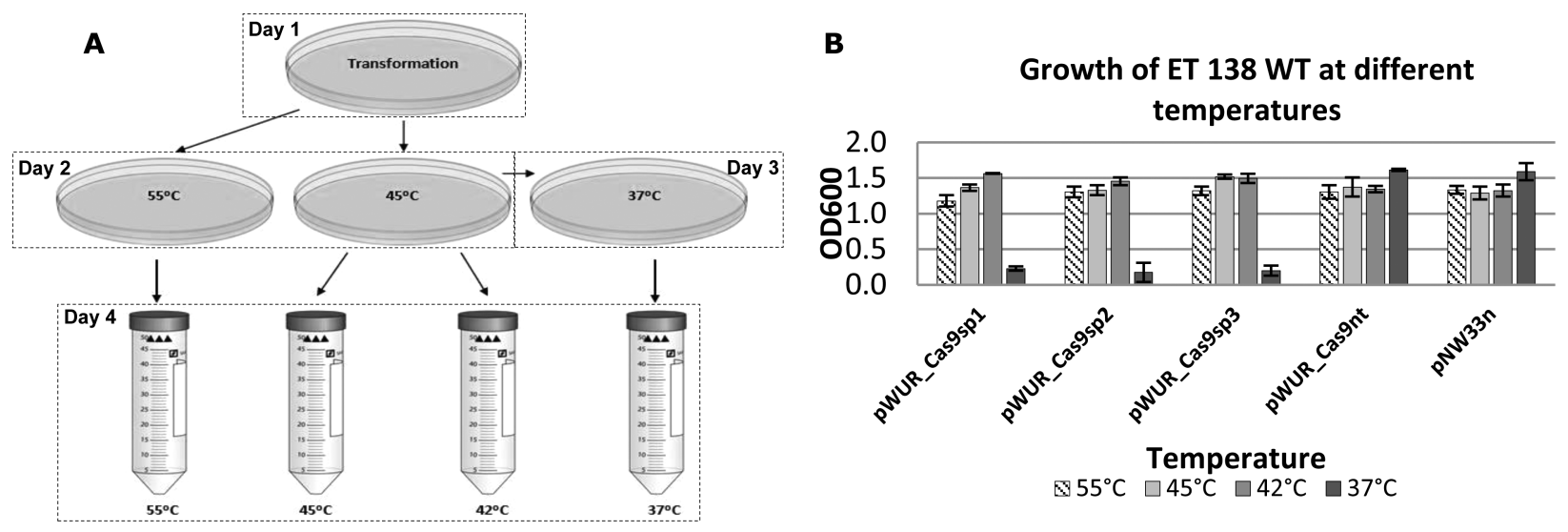

Figure 2. (A) Sequential transfer scheme of wild-type ET 138 cultures to evaluate spCas 9 expression and targeting efficiency at different temperatures. ET 138 cells were transformed with the pWUR_Cas9sp1, pWUR_Cas9sp2, pWUR_Cas9sp3, pWUR_Cas9nt, and pNW33n vectors and plated on LB2 agar plates with chloramphenicol (day 1). After overnight $(\mathrm{ON})$ incubation at $5 \overline{5}^{\circ} \mathrm{C}$, single colonies were restreaked on LB2 agar plates with chloramphenicol and incubated $\mathrm{ON}$ at 55 and $45{ }^{\circ} \mathrm{C}$ (day 2). Colonies from the $45{ }^{\circ} \mathrm{C}$ plates were transferred to LB2 agar plates with chloramphenicol for $\mathrm{ON}$ incubation at $37^{\circ} \mathrm{C}$ (day 3). The plates from days 2 and 3 were then used for inoculation of liquid medium (day 4); 1 colony per 55,45 , and $37^{\circ} \mathrm{C}$ plate was transferred to LB2 medium with xylose, glucose, and chloramphenicol for ON incubation at 55 , 45 , and 37 ${ }^{\circ} \mathrm{C}$, respectively, while one extra colony per $45{ }^{\circ} \mathrm{C}$ plate was transferred to the same medium for ON incubation at $42{ }^{\circ} \mathrm{C}$. (B) Results of the targeting experiment showing $\mathrm{OD}_{600}$ measurements from cultures of wild-type ET 138 transformed with the three different pyrF targeting cas $9_{s p}$ constructs, the nontargeting cas $9_{s p}$ construct, and pNW33n. The growth of the cells with the $p y r F$ targeting constructs is greatly affected at $37^{\circ} \mathrm{C}$, which is not observed for cells containing the nontargeting constructs.

the expression of $\operatorname{cas} 9_{s p}$ is not toxic for ET 138 cells at any of the tested temperatures.

In Vivo Validation of spCas9 Activity at Different Temperatures. As the B. smithii genome encompasses genes for the basic prokaryotic NHEJ-like system, ${ }^{31,32}$ our first approach to construct a spCas9-based genome editing tool focused on determining the in vivo temperature limits of spCas9 and the capacity of the ET 138 NHEJ-like mechanism to repair spCas9-induced DSDBs. We chose to target pyrF as a first proof of principle. The pyrF gene encodes the orotidine 5'phosphate decarboxylase and is part of the operon for pyrimidine biosynthesis. Removal of the gene causes uracil auxotrophy and resistance to the toxic uracil analogue 5fluorootic acid (5-FOA). It is a frequently used selection and counterselection system in many organisms including thermophiles, $^{50-52}$ and to this end, we initially made a clean $p y r F$ deletion mutant ET $138 \Delta l d h L \Delta s i g F \Delta p y r F$ by adding the fused $1 \mathrm{~kb}$ up- and downstream pyrF flanks to pNW33n and applying 5-FOA pressure to select for double crossover mutants. A total of nine rounds of subculturing on selective media containing uracil and 5-FOA were required before pure knockouts were obtained with a knockout efficiency of around $50 \%$ (data not shown), making the process rather time consuming. Whereas integration of pNW33-based HR plasmids in ET 138 strains occurs, ${ }^{15}$ likely due to the rolling circle-based replication of pNW33n, ${ }^{53,54}$ subsequent excision of the plasmid and identification of clean mutant strains is difficult. ${ }^{15}$ The speed and ease of this process could be significantly increased by using a strong counterselection system, such as spCas9.

We continued our study by constructing three vectors based on the pWUR_Cas9nt sequence, designated pWUR_Cas9sp1, pWUR_Cas9sp2, and pWUR_Cas9sp3, each containing a different pyrF-targeting spacer (sp1-3). We transformed a single batch of wild-type ET 138 competent cells with the three targeting vectors, the nontargeting control pWUR_Cas9nt, and the empty vector control pNW33n. After initial outgrowth at $55{ }^{\circ} \mathrm{C}$ on LB2 plates without sugar, one confirmed transformant for each construct was subjected to a sequential plating and culturing process in which the temperature was stepwise decreased from 55 to $37{ }^{\circ} \mathrm{C}$ to induce spCas 9 expression (Figure 2A). Normal growth was observed for all cultures at 55, 45 , and $42{ }^{\circ} \mathrm{C}$, as well as for the control cultures at $37^{\circ} \mathrm{C}$. No growth was observed for any of the cultures with pyrF-targeting sgRNA modules at $37{ }^{\circ} \mathrm{C}$ (Figure $2 \mathrm{~B}$ ). We repeated the transformation and culturing process using the double mutant B. smithii ET138 $\Delta l d h L \Delta s i g F$ strain. ${ }^{15}$ This strain is sporulation-deficient, it cannot produce L-lactate, and it was constructed as the basic platform strain for further metabolic engineering work. We obtained similar results as those for the wild-type B. smithii ET138 strain (Figure S3), and we continued our study using the double mutant strain.

In line with the in vitro assay data, the aforementioned results indicate that the designed spCas 9 system is active at $37^{\circ} \mathrm{C}$ but inactive and does not introduce lethal DSDBs to the ET 138 genome at temperatures from $42{ }^{\circ} \mathrm{C}$ and above. It also indicates that the NHEJ system in ET 138 is inactive at $37{ }^{\circ} \mathrm{C}$ or not active enough to counteract the spCas 9 activity. In addition, the sequencing results of the pWUR_Cas9sp 2 construct revealed the deletion of seven nucleotides near the $3^{\prime}$ end of $\mathrm{P}_{\text {pta }}$ (Figure S2). However, the results of the targeting experiment support our hypothesis that the uncharacterized nature of $\mathrm{P}_{\text {pta }}$ and possibly the extra nucleotides at the $5^{\prime}$ end of the sgRNA module, does not hinder the targeting efficiency of spCas9. Moreover, the truncated $\mathrm{P}_{\text {pta }}$ of the pWUR_Cas9sp 2 construct clearly expresses enough sgRNA molecules, and the observed seven-nucleotide long deletion has no impact to the targeting efficiency of the corresponding spCas9/sgRNA complex. The latter two observations reveal that our system tolerates a certain level of flexibility in the 5 -extension of the sgRNA molecule.

Efficient Gene Deletion Using a HR-CRISPR-Cas9 Counterselection System. Taking into account the results described so far, we decided to develop a Cas9-based editing system for ET 138 that exploits its efficient homologous recombination mechanism ${ }^{15}$ and the temperature-induced spCas 9 activity at $37^{\circ} \mathrm{C}$. The new experimental setup consists of a single plasmid that combines the recombination template 

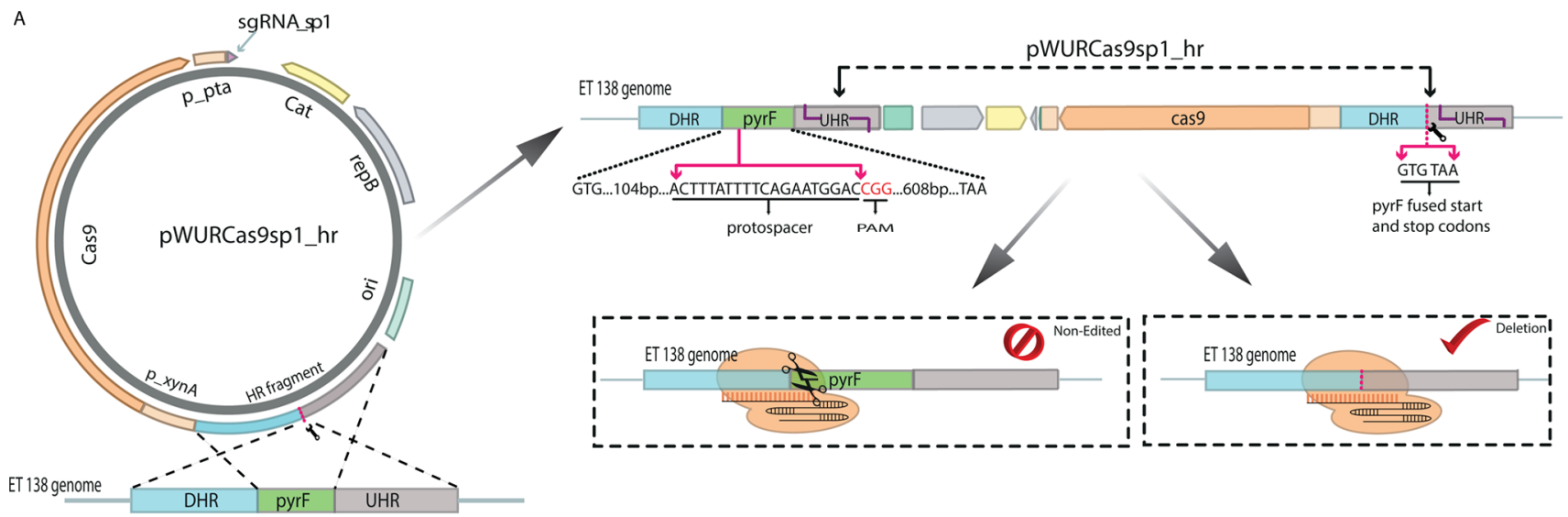

B
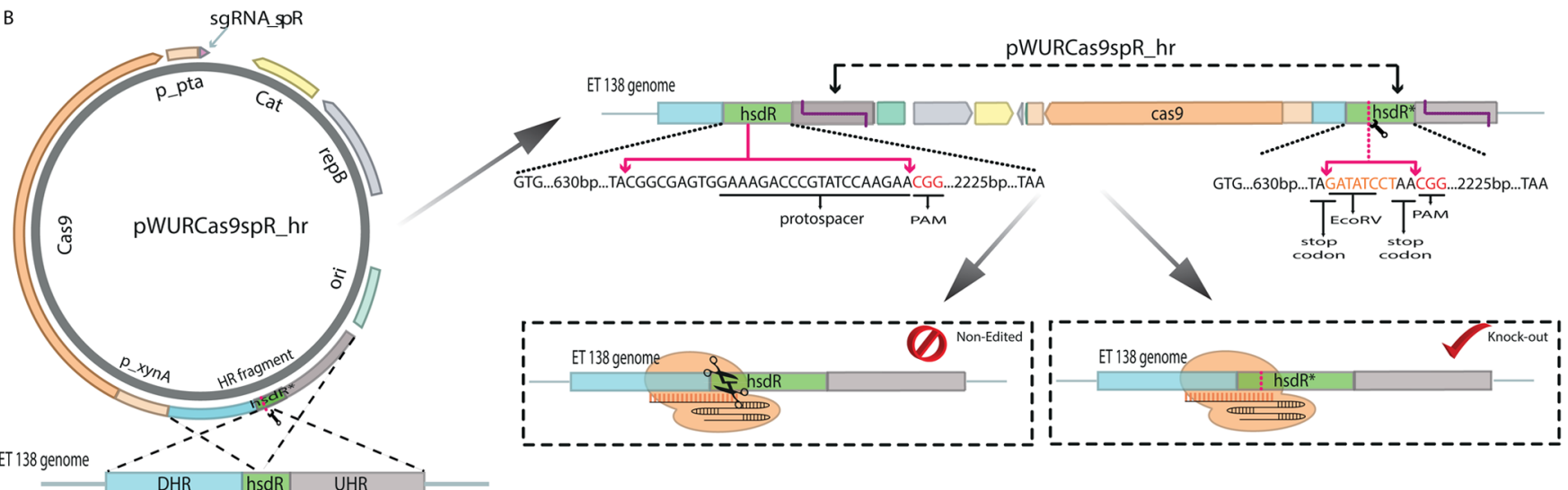

C
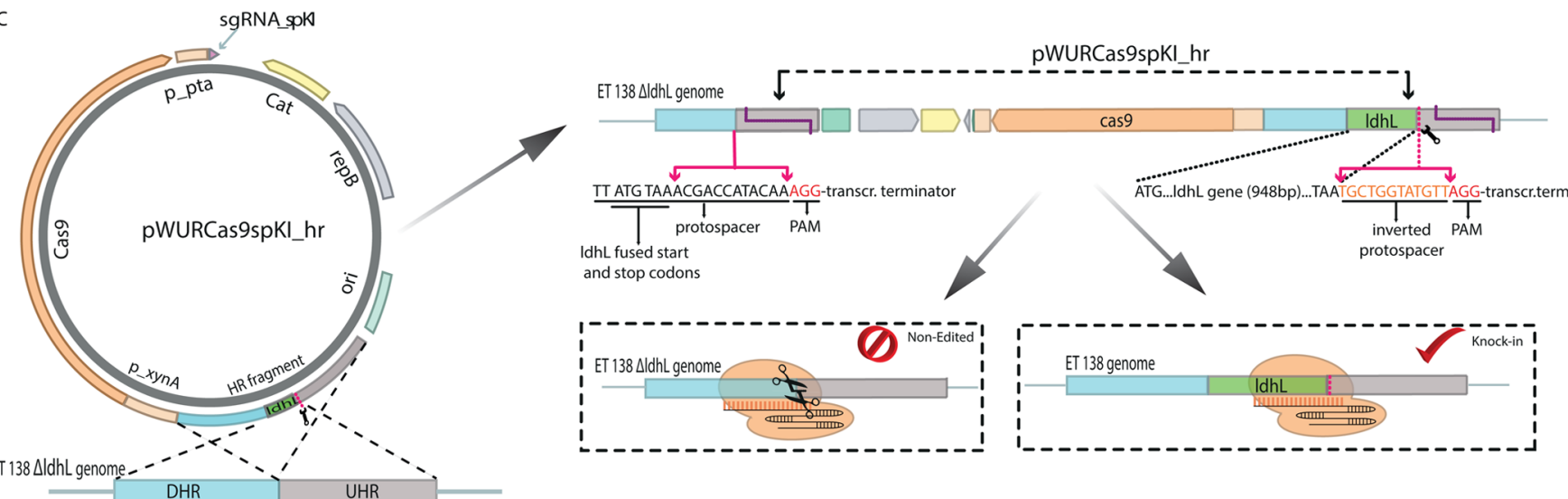

Figure 3. Schematic representation of the different homologous recombination and spCas9-mediated mutations described in this study. The first single crossover event (SCO) can occur by insertion of the editing plasmid into the chromosome either through the upstream homologous region (UHR), as depicted here, or through the downstream homologous region (DHR). (A) Gene deletion. A scar-less, markerless pyrF gene deletion was established after insertion of the editing vector into the chromosome via homologous recombination with the plasmid-borne editing template $(2 \times 1$ $\mathrm{kb}$ flanks, immediately flanking the pyrF gene and thus removing it from start to stop codon), after which a second SCO event results in either wildtype revertants or edited cells. The spCas 9 targeting of the wild-type cells acts as counterselection for the pyrF mutants. (B) Gene knockout via insertion of stop codons and a restriction site. The followed process was similar to the gene deletion described above. The $h s d R$ restriction gene was inactivated by inserting stop codons and a restriction site between codons 212 and 221 that were contained in a $2 \mathrm{~kb}$ HR fragment that expands 289 bp upstream and $1.65 \mathrm{~kb}$ downstream from the start codon of the $h s d R$ gene on the genome of the ET 138. Between the two stop codons, an EcoRV restriction site was added, generating a frame shift and facilitating the screening process. The spacer was designed to target the original sequence without stop codons and restriction site. (C) Gene knock-in. The followed process was similar to the gene deletion and gene knockout processes described above. The $l d h L$ gene was reinserted into mutant strain ET $138 \Delta l d h L \Delta s i g F$. This was achieved by adding the original $l d h L$ gene sequence between $2 \times 1 \mathrm{~kb}$ HR flanks. The spacer was designed to target the area between the ldhL stop codon and the beginning of the adjacent rhoindependent transcriptional terminator. On the HR flanks, the region between the ldhL stop codon and its rho-independent transcriptional terminator was inverted, avoiding the spCas9 targeting of edited cells. 
A
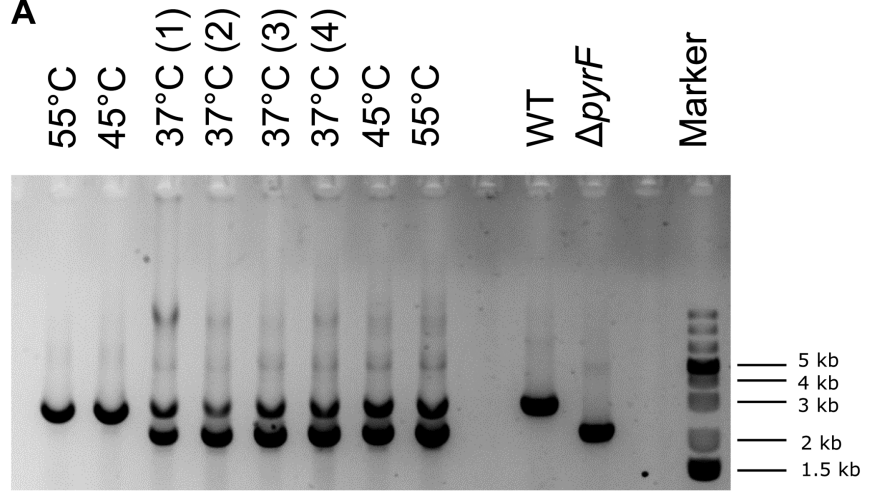

B

TVMY $_{\mathbf{x g}}+$ uracil

TVMY

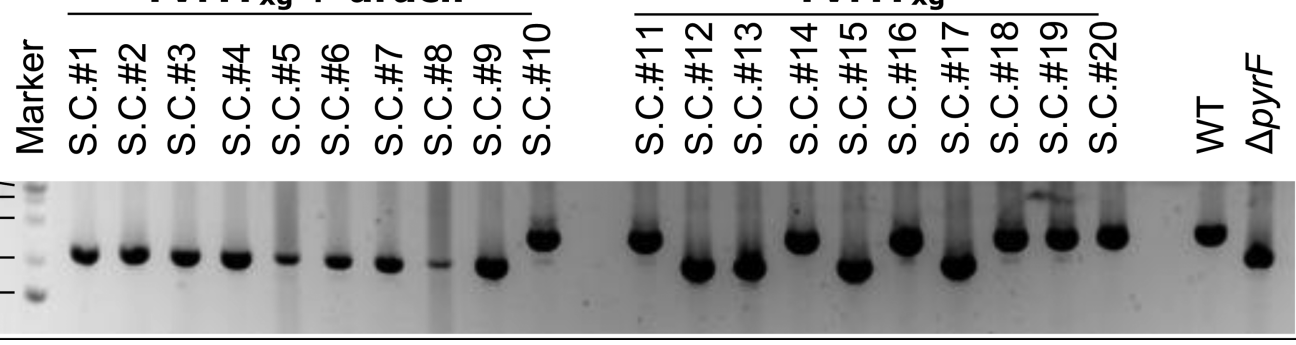

Figure 4. (A) Agarose gel electrophoresis showing the results from PCR on the genomic DNA of a ET $138 \Delta l d h L \Delta$ sigF culture transformed with pWUR_Cas9sp1_hr and sequentially transferred to different temperatures (following the depicted temperature sequence) for detection of pyrF deletion mutants in the culture mixture. The pyrF deletion mutant band appears from the first $37^{\circ} \mathrm{C}$ culturing step (lane 3) onward. The last 2 lanes are the negative (wild-type) and positive $(\Delta p y r F)$ controls, which correspond to 2.9 and $2.1 \mathrm{~kb}$ DNA fragments, respectively. (B) Agarose gel electrophoresis showing the resulting products from colony PCR on colonies transformed with pWUR_Cas9sp1_hr for the detection of deletion mutants. Nine out of the 10 tested colonies (S.C.\#1 to S.C.\#10) that resulted from the 3-day long editing process in TVMY ${ }_{\mathrm{xgu}}$ (TVMY supplemented with xylose, glucose, and uracil) medium were deletion mutants. Four out of the 10 tested colonies (S.C.\#11 to S.C.\#20) that resulted from the 3-day long editing process in $\mathrm{TVMY}_{\mathrm{xg}}$ (TVMY supplemented with xylose and glucose) medium were deletion mutants. The last 2 lanes are the negative (wild-type) and positive $(\Delta p y r F)$ controls, respectively.

and the spCas9- and sgRNA-expressing modules. Providing the cells with the appropriate plasmid-borne editing template at 55 ${ }^{\circ} \mathrm{C}$ and then inducing the expression of active spCas 9 at $37{ }^{\circ} \mathrm{C}$ through a sequential culturing process is expected to form a powerful homologous recombination and counterselection system. To generate a $p y r F$ deletion mutant, pWUR_Cas9sp1 was selected as the pyrF-targeting vector for further experiments, which was always compared to the nontargeting control, pWUR Cas9nt. To both vectors, we added a fusion of the two pyrF flanks (each $1 \mathrm{~kb}$ ), creating the pWUR_Cas9nt_hr and pWUR_Cas9sp1_hr vectors (i.e., hr, for homologous recombination) (Figure $3 \mathrm{~A}$ ). After transforming the four constructs (two with flanks and two without flanks) into ET $138 \Delta l d h L$ $\Delta s i g F$ at $55{ }^{\circ} \mathrm{C}$, one verified transformant per construct was inoculated into TVMY selection medium containing xylose and glucose and supplemented with uracil $\left(\mathrm{TVMY}_{\mathrm{xgu}}\right)$ to complement the auxotrophy in the case of successful pyrF deletion. After growth at $55{ }^{\circ} \mathrm{C}$ for $24 \mathrm{~h}$, cells were sequentially transferred every $24 \mathrm{~h}$ to fresh media while gradually decreasing the culturing temperature from 55 to $37^{\circ} \mathrm{C}$, with an intermediate transfer at $45{ }^{\circ} \mathrm{C}$. After three more transfers at $37{ }^{\circ} \mathrm{C}$ to allow for efficient spCas 9 counterselection, cells were transferred back to $55{ }^{\circ} \mathrm{C}$ with an intermediate transfer at 45 ${ }^{\circ} \mathrm{C}$, allowing for gradual adjustment of their metabolism. As expected, PCR on genomic DNA from the pWUR_Cas9nt and pWURCas9_sp1 cultures showed no pyrF knockout bands at any culturing temperature due to the lack of a homologous recombination template in the constructs. In line with the initial in vivo tests, pWURCas9_sp1 cultures at $37^{\circ} \mathrm{C}$ showed almost no growth, whereas the pWUR_Cas9nt cultures at all temperatures showed the expected growth for ET 138. PCR on genomic DNA from the liquid cultures containing the vectors with pyrF flanks showed the absence of knockout bands for the pWUR_Cas9nt_hr cultures from the first culturing step at $37^{\circ} \mathrm{C}$ onward, but very strong pyrF knockout bands for the pWUR_Cas9sp1_hr cultures for the same culturing steps mentioned above (Figure 4A). The striking difference in the density of the knockout bands between the targeting pWUR_Cas9sp1_hr and the nontargeting pWUR_Cas9nt_hr cultures indicates successful spCas9 activity and pyrF targeting by the pWUR_Cas9sp1_hr construct. It furthermore indicates that the counterselection activity of spCas9 is already efficient from the first culturing step at $37{ }^{\circ} \mathrm{C}$. Growth of the pWUR_Cas9nt_hr cultures was similar to the control at all temperatures, whereas the pWUR_Cas9sp1_hr cultures showed poor growth in the first two culturing steps at $37^{\circ} \mathrm{C}$, but the growth was reconstituted to control levels from the third culturing step at $37{ }^{\circ} \mathrm{C}$ onward (Figure S4). After an upshift in the temperature, colony PCR of the $55{ }^{\circ} \mathrm{C}$ colonies showed that 5 out of 10 tested pWUR_Cas9sp1_hr colonies were pure $p y r F$ deletion mutants, i.e., an editing efficiency of $50 \%$ for our system (data not shown). The correct mutations were also verified by sequencing. None of the 10 tested pWUR_Cas9nt_hr colonies (nontargeting control) were pyrF deletion mutants, demonstrating functional spCas9 targeting. 
A

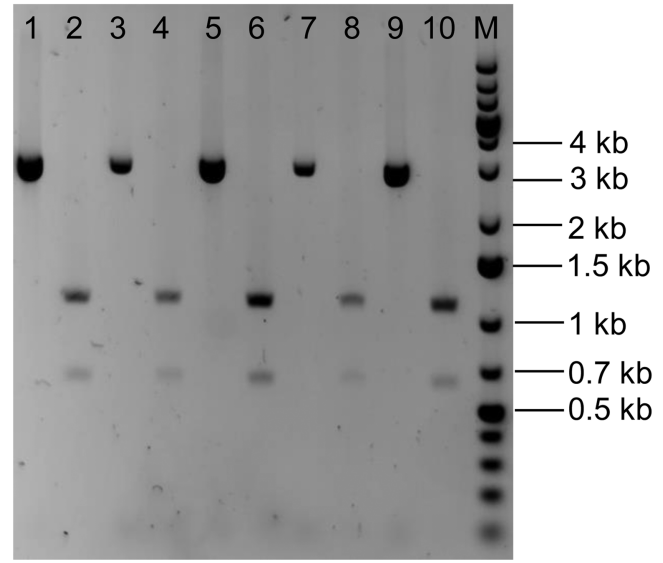

B

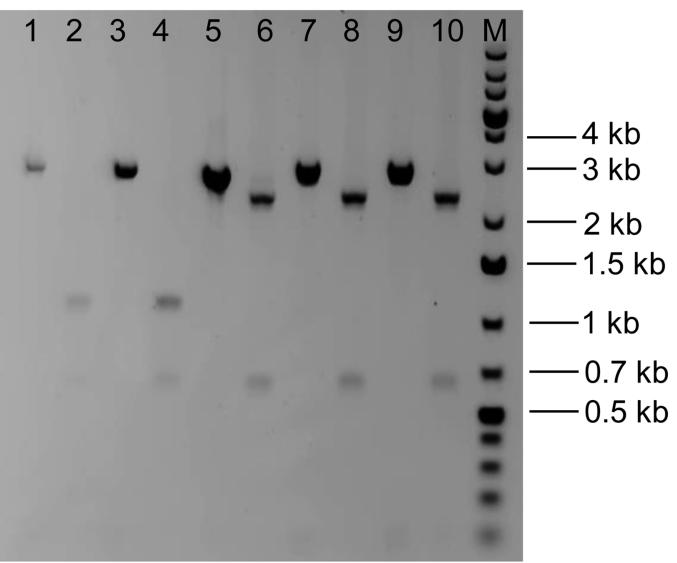

Figure 5. (A) Agarose gel electrophoresis showing the resulting products from colony PCR on ET 138 colonies transformed with pWUR_Cas9spR_hr for the detection of $h s d R$ knockout mutants from the 3-day long editing process in $\mathrm{LB}_{\mathrm{xg}}$ medium. The $2.75 \mathrm{~kb}$ PCR fragments resulting after using genome-specific primers (lanes $1,3,5,7,9$ ) were digested with the EcoRV restriction enzyme. Each digestion mixture was loaded next to its corresponding undigested PCR fragment (lanes 2, 4, 6, 8, 10). All colonies evaluated were shown to be knockout mutant cells as the restriction digestion gave the expected bands of 1.1, 1.05, and $0.6 \mathrm{~kb}$. (B) Agarose gel electrophoresis showing the resulting products from colony PCR on ET 138 colonies transformed with pWUR_Cas9spR_hr for the detection of hsdR knockout mutants from the 3-day long editing process in $\mathrm{TVMY}_{\mathrm{xg}}$ medium. The $2.75 \mathrm{~kb}$ PCR fragments resulting after using genome-specific primers (lanes 1, 3, 5, 7, 9) were digested with the EcoRV restriction enzyme. Each digestion mixture was loaded next to its corresponding undigested PCR fragment (lanes 2, 4, 6, 8, 10). For the two colonies composed of knockout mutant cells (lanes 1-2 and 3-4), the restriction digestion gives the expected bands of $1.1,1.05$, and $0.6 \mathrm{~kb}$. For the three nonedited colonies composed of wild-type cells (lanes 5-6, 7-8, 9-10), the restriction digestion gives the expected bands of 2.15 and $0.6 \mathrm{~kb}$.

To improve the efficiency and speed of the system, we repeated the process for the pWUR_Cas9sp1_hr-containing strain and reduced the number of culturing steps at $37^{\circ} \mathrm{C}$ from 4 to 1 while keeping the culturing time of each step in a window between 8 and $16 \mathrm{~h}$. Moreover, we used three different media in order to observe possible medium-dependent variations in the efficiency of the system: TVMY selection medium supplemented with xylose, glucose, and uracil $\left(\mathrm{TVMY}_{\mathrm{xgu}}\right)$; TVMY selection medium supplemented with xylose and glucose but not with uracil $\left(\mathrm{TVMY}_{\mathrm{xg}}\right)$; and LB2 medium supplemented with xylose and glucose $\left(\mathrm{LB} 2_{\mathrm{xg}}\right)$. After the final culturing step at $55{ }^{\circ} \mathrm{C}$, cells were plated on selective agar of the corresponding medium, supplemented with uracil. Colony PCR on 10 randomly selected colonies for each medium and construct showed that 9 out of 10 colonies were pure $p y r F$ deletion mutants colonies from the culturing process on $\mathrm{TVMY}_{\mathrm{xgu}}$ medium (Figure 4B). From the process with $\mathrm{TVMY}_{\mathrm{xg}}$ medium, 4 of the examined colonies were pure $\mathrm{pyr} F$ deletion mutants, proving the efficiency of the counterselection tool even in the presence of an auxotrophy barrier (Figure 4B). The process with $\mathrm{LB} 2_{\mathrm{xg}}$ medium was repeated twice, with two different pWUR_Cas9sp1_hr containing ET 138 clones. Surprisingly, all colonies evaluated from the LB2 medium process (40 in total) contained the wild-type pyrF gene (data not shown). At this moment, it is unclear as to what causes this difference between the $\mathrm{LB} 2_{\mathrm{xg}}$ medium and the two types of TVMY media, and this will be addressed in future research.

To retain spCas9 activity, antibiotics were added in all steps. To allow for subsequent metabolic engineering steps, however, plasmid curing is required. After transferring a sequenceverified pyrF deletion mutant twice in TVMY medium without antibiotics, cells were plated on TVMY plates without antibiotics. Colony PCR with plasmid-specific primers showed that all eight tested colonies had lost the plasmid. Finally, we verified the 5-FOA sensitivity and the uracil auxotrophy of two
ET $138 \Delta l d h L \Delta s i g F \Delta p y r F$ cultures that originated from two of the tested colonies ET 138 (Figure S5).

Expanding the Toolbox: Knocking Out the Type I RM System. To increase the potential of ET 138 as a platform organism for the production of green chemicals, we aimed to improve its transformation efficiency. ET 138 has a type I restriction-modification (R-M) system. Methylation analysis of the PacBio genome sequencing data showed the existence of the single motif "Cm6AGNNNNNNTGT/ACm6ANNNNNNCTG" with N6-methyladenine (m6A) modifications (unpublished data). Our attempts to transform different pNW33nbased constructs containing one or multiple copies of this motif were unsuccessful or gave 3-orders of magnitude lower transformation efficiencies compared to those with constructs of the same size that do not contain the aforementioned motif. We decided to knock out the $h s d R$ restriction gene of the $B$. smithii ET138 type I R-M system, expecting to overcome the transformation obstacle and further expand its genetic accessibility.

For knocking out the $h s d R$ gene, we followed a different approach compared to the $p y r F$ deletion process to evaluate the efficiency of the Cas9-based counterselection editing method in the introduction of limited-sized modifications to the genome. Between the origin of replication (ori) and the cas $9_{s p}$ gene of the pWUR_Cas9nt vector, we introduced a 1920 bp HR fragment that resulted from the fusion of two separate fragments: one that is composed of the $924 \mathrm{bp}$ upstream of codon 212 of the $h s d R$ gene (including the two first nucleotides of the codon) and one that is composed of the $986 \mathrm{bp}$ downstream of codon 221 of the $h s d R$ gene. In this HR fragment, we replaced the $25 \mathrm{nt}$ part between codons 212 and 221 of the $h s d R$ gene, including the last nucleotide of codon 212 , with an $8 \mathrm{nt}$ sequence composed of two stop codons and an EcoRV restriction site, generating a frame shift and facilitating the screening process (Figure 3B). Since the $h s d R$ gene is 2952 nucleotides ( 984 codons) long, only one-fifth of it 


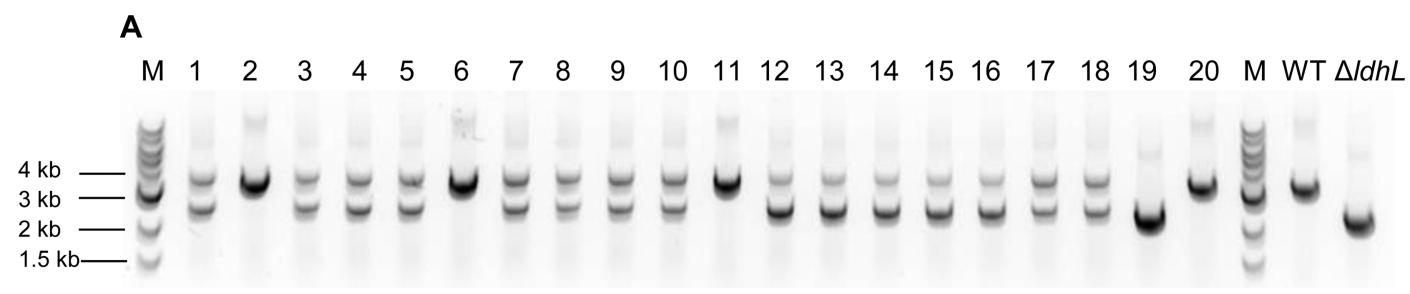

B

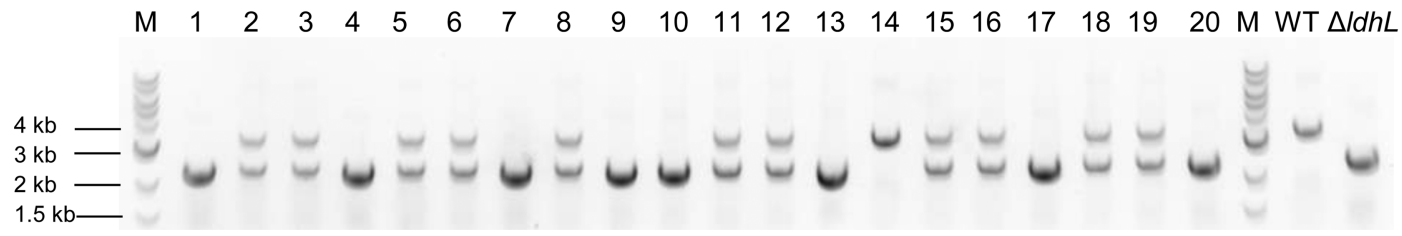

Figure 6. Agarose gel electrophoresis showing the resulting products from colony PCR from the 3-day long ldhL knock-in culturing processes in LB2 medium, using ET $138 \Delta l d h L \Delta s i g F \Delta h s d R$ cells transformed with the pWUR_Cas9spKI_hr1 vector. For the colony PCR, genome-specific primers BG8145 and BG8146 were used with the expected size of the PCR fragment for the knock-in mutations being $3.2 \mathrm{~kb}$ (equal to the size of the PCR fragment for the wild-type cells). The expected size of the PCR fragment for the knockout (nonedited) mutants was $2.3 \mathrm{~kb}$. (A) When the $45{ }^{\circ} \mathrm{C}$ culturing step was performed, the process resulted in 4 out of the 20 tested colonies having the knock-in genotype (20\% editing efficiency), 15 colonies with mixed knock-in and wild-type genotype, and only 1 colony with wild-type genotype. (B) When the $45^{\circ} \mathrm{C}$ culturing step was omitted, the process resulted in only 1 out of the 20 tested colonies having the knock-in genotype, 11 colonies with mixed genotype, and 8 colonies with the wild-type genotype.

will be translated due the introduction of the stop codons. We also introduced a spacer in the sgRNA module for spCas9 targeting of the unmodified genomes, completing the construction of the pWUR_Cas9spR_hr editing vector.

B. smithii ET138 $\Delta l d h L \bar{\Delta}$ sigF cells were transformed with the new vector and sequentially cultured as before, gradually decreasing the temperature from 55 to $37{ }^{\circ} \mathrm{C}$, with an intermediate transfer at $45{ }^{\circ} \mathrm{C}$, and then increasing it back to 55 ${ }^{\circ} \mathrm{C}$. The duration of each culturing step was within a window of 8 to 16 h. Moreover, we used two types of selection media, $\mathrm{LB}_{\mathrm{xg}}$ and $\mathrm{TVMY}_{\mathrm{xg}}$. Five transformants per medium were subjected to colony PCR, after which the PCR fragments were digested with EcoRV. All colonies from the LB2-culturing process were successfully modified (Figure 5A), giving 100\% editing efficiency, whereas only two of the colonies from the TVMY process were modified, giving $40 \%$ editing efficiency (Figure 5B). This is in contrast with the result from the $p y r F$ deletion process, where there were no modified colonies resulting from the LB2-culturing process. This suggests that the selection of culturing medium influences the efficiency of our editing system in a variable and gene-specific manner. Plasmid curing was performed as before, and the correct mutations were verified by sequencing.

We confirmed the lack of a functional R-M system in the newly developed ET $138 \Delta l d h L \quad \Delta s i g F \quad \Delta h s d R$ strain by successfully transforming the plasmid-cured cells with vector pG2K (Table S2). ${ }^{55}$ In previous attempts, we did not succeed in transforming this vector into other $(h s d R+)$ ET 138 strains as it contains the aforementioned methylation motif in its antibiotic resistance marker gene, the kanamycin nucleotidyltransferase (aadA) gene derived from Geobacillus stearothemophilus. $^{55}$ In this way, we added a new antibiotic resistance marker to the toolbox of ET 138, and we confirmed that the ET $138 \Delta l d h L \Delta$ sigF $\Delta h s d R$ strain can be utilized for the expansion of the genetic parts toolbox.

Metabolic Engineering Using spCas9: Knock-In of the IdhL Gene. Next, we evaluated the applicability of our Cas9based system in markerless gene chromosomal integrations by knocking the 942 bp long genomic fragment between the start and stop codons of the lactate dehydrogenase (ldhL) gene into the genome of ET $138 \Delta l d h L \Delta s i g F \Delta h s d R$. The reconstitution of lactate production in the resulting ET $138 \Delta s i g F \Delta h s d R$ strain would allow for efficient growth under anaerobic conditions, while retaining the advantages of a sporulationand R-M-deficient strain.

Two versions were constructed of a pWUR_Cas9-based vector that target the ET $138 \Delta l d h L \Delta s i g F \Delta h s d \bar{R}$ genome at the same position between the $l d h L$ stop codon and the beginning of the adjacent rho-independent transcriptional terminator. HR was facilitated with $1 \mathrm{~kb}$ flanks (pWUR_Cas9spKI_hr1) or $0.75 \mathrm{~kb}$ flanks (pWUR_Cas9spKI_hr2). For both versions, the region between the $l d \overline{h L}$ stop codon and its rho-independent transcriptional terminator was inverted, avoiding spCas9 targeting (Figure 3C). Wild-type ldhL sequence was inserted in the region between the start and stop codons to allow it to be knocked in.

ET138 $\Delta l d h L \Delta s i g F \Delta h s d R$ was transformed with the two pWUR_Cas9spKI_hr versions, and the transformants were sequentially cultured as described before, gradually decreasing the temperature from 55 to $37{ }^{\circ} \mathrm{C}$, with or without an intermediate transfer step at $45{ }^{\circ} \mathrm{C}$, and then increasing it back to $55^{\circ} \mathrm{C}$. Each culturing step was within a window of 8 to $16 \mathrm{~h}$. Again, we used two types of selection media, $\mathrm{LB} 2_{\mathrm{xg}}$ and TVMY $_{\mathrm{xg}}$. The colony PCR results of the TVMY culturing processes showed that none of the tested colonies had the knock-in genotype. The colony PCR results of the LB2 culturing processes with the pWUR_Cas9spKI_hr1 transformant showed that with the additional culturing step at 45 ${ }^{\circ} \mathrm{C}$, 4 out of the 20 tested colonies had the knock-in genotype (20\% editing efficiency), 15 colonies had a mixed knock-in/ wild-type genotype, and only 1 colony had the wild-type genotype (Figure 6A). When the culturing step at $45{ }^{\circ} \mathrm{C}$ was omitted, only 1 out of the 20 tested colonies had the knock-in genotype, 11 colonies had the mixed genotype, and 8 colonies had the wild-type genotype (Figure 6B). The colony PCR results of the LB2 culturing processes with the pWUR_- 
Cas9spKI hr2 transformant showed that with the additional culturing step at $45^{\circ} \mathrm{C}, 1$ out of the 20 tested colonies had the knock-in genotype ( $5 \%$ editing efficiency), 7 colonies had the mixed knock-in and wild-type genotype, and only 1 colony had the wild-type genotype (Figure S6A). When the culturing step at $45{ }^{\circ} \mathrm{C}$ was omitted, none of the 20 tested colonies had the knock-in genotype, only 6 colonies had the mixed genotype, and the remaining 14 colonies had the wild-type genotype (Figure S6B). This was the first time that we observed colonies with a mixed genotype using our editing approach. The appearance of such colonies could be explained by relatively inefficient Cas9 targeting when the enzyme is loaded with a suboptimal sgRNA module, as has been described for E. coli, ${ }^{56}$ although the molecular basis for this phenomenon remains elusive. Alternative sgRNAs may lead to a more stringent counterselection, thereby improving the editing efficiency. Additionally, the difference in recombination efficiency at specific chromosomal sites might influence the editing efficiency of the tool. ${ }^{35}$ In a recent study that combined dsDNA recombineering with Cas9 counterselection, the efficiency of the employed system for insertions was lower than the efficiency for deletions, whereas longer homologous regions led to higher editing efficiencies. ${ }^{44}$ Our results confirm the influence of the HR template length and the importance of the culturing period before the induction of counterselection. The editing efficiency of the tool was higher when we employed the editing construct with the $1 \mathrm{~kb}$ HR flanks compared to the editing construct with the $0.75 \mathrm{~kb}$ HR flanks ( 20 vs 5\% efficiency, respectively; Figure S6). Furthermore, we observed that a culturing period with an additional intermediate step at $45{ }^{\circ} \mathrm{C}$ allows for efficient homologous recombination and double crossover events to occur, leading to the appearance of the mutants for which Cas9 will select. This is in line with observations in Lactobacillus reuteri ${ }^{57}$ and supports our findings that the efficiency of using spCas 9 as a counterselection tool is higher compared to that using spCas9 as a tool for the induction of the cellular HR mechanism after introduction of targeted DSDBs. In addition, it may be that the stress of decreasing the temperature increases the efficiency of the homologous recombination mechanism.

Next, we attempted to cure the constructed B. smithii ET138 $\Delta s i g F \Delta h s d R$ strain from the pWUR_Cas9spKI_hr1 plasmid using the sequential transferring approach in LB2 medium without antibiotic at $55{ }^{\circ} \mathrm{C}$. However, after the usual two transfers, none of the tested colonies had lost the plasmid. We repeated the same sequential transferring process but increased the culturing temperature to $65^{\circ} \mathrm{C}$, as the pNW33n replicon might be less stable at elevated temperatures. ${ }^{15}$ After two transfers at $65{ }^{\circ} \mathrm{C}, 1$ out of 8 tested colonies was confirmed to be plasmid-free by PCR and antibiotic sensitivity, and the correct mutations were verified by sequencing. Plasmid curing might be simplified in the future by adding an sgRNA expressing module with a spacer against the editing plasmid to the system. ${ }^{44,58}$ The module will have to either be under the control of a tightly inducible promoter or cloned into a second expression vector and transformed into the edited cells in a second transformation round.

Finally, evaluation of lactate production in the resulting $B$. smithii ET138 $\Delta s i g F \Delta h s d R$ strain under aerobic, microaerobic, and anaerobic conditions showed a complete restoration of lactate production to wild-type levels (Table S4).

\section{CONCLUSIONS}

In this study, spCas9-based genome editing was applied for the first time to a moderate thermophile, establishing a gene deletion, a gene knockout, and a gene insertion. A major advantage of this system is the requirement of only one plasmid without inducible or highly characterized promoters to drive spCas9 and sgRNA expression. Additionally, the speed and efficiency of the genome editing process of ET 138 has been substantially improved compared to that of the previous lacZbased counterselection system. For the three cases presented in this study, it took on average 1 week from transformation to clean deletion, knock out, or knock in (including the plasmid curing step), with an editing efficiency of $90 \%$ for the gene deletion, $100 \%$ for the gene knock out, and $20 \%$ for the gene insertion.

Over the course of our study, we showed that spCas9 is not active in vivo from $42{ }^{\circ} \mathrm{C}$ and above. This observation allowed us to develop an editing system where mutants are constructed via homologous recombination events at higher temperatures $\left(\geq 42{ }^{\circ} \mathrm{C}\right)$ before Cas9-induced counterselection takes place at $37^{\circ} \mathrm{C}$. The crucial factors for obtaining high editing efficiencies are giving sufficient time for $\mathrm{HR}$ at elevated temperatures before starting the spCas9-based counterselection, and the length of the HR flanks. Moreover, we hypothesize that testing different sgRNA modules may improve the editing efficiency of the tool. During our study, we observed gene-dependent differences in the number of obtained mutants when repeating the same process using different media. There is no obvious link between the editing of a specific gene and the medium used for the editing process, and this will be the subject of further studies.

The results of the editing approach that we developed make our system potentially applicable for many interesting model or nonmodel organisms with an active HR mechanism and a growth temperature range covering 37 to $\geq 42{ }^{\circ} \mathrm{C}$. It is anticipated that the approaches reported here will expand the range of organisms for which the powerful Cas9 counterselection tool can be used, thereby greatly increasing engineering throughput for these organisms and allowing for both their fundamental study and biotechnological exploitation.

\section{MATERIALS AND METHODS}

Bacterial Strains and Growth Conditions. Strains used in this study are listed in Table S1. All B. smithii strains were routinely cultured at $55{ }^{\circ} \mathrm{C}$ unless stated otherwise. TVMY medium and LB2 medium were used as described previously. ${ }^{15}$ TVMY $_{\mathrm{xgu}}$ is TVMY supplemented with $0.5 \mathrm{~g} / \mathrm{L}$ xylose, $0.5 \mathrm{~g} / \mathrm{L}$ glucose, and $50 \mathrm{mg} / \mathrm{L}$ uracil. TVMY ${ }_{\mathrm{xg}}$ is TVMY supplemented with $0.5 \mathrm{~g} / \mathrm{L}$ xylose and $0.5 \mathrm{~g} / \mathrm{L}$ glucose. $\mathrm{LB} 22_{\mathrm{xg}}$ is $\mathrm{LB} 2$ supplemented with $0.5 \mathrm{~g} / \mathrm{L}$ xylose and $0.5 \mathrm{~g} / \mathrm{L}$ glucose. Substrates were added separately as $50 \%$ autoclaved solutions after autoclaving the medium. Uracil was added as a $50 \mathrm{mg} / \mathrm{mL}$ filter sterilized solution in $1 \mathrm{M} \mathrm{NaOH}$ after autoclaving the medium and addition of the substrates. E. coli strains were grown in LB medium at $37^{\circ} \mathrm{C}$. For plates, $30 \mathrm{~g}$ of agar (Difco) per liter of medium was used for B. smithii in all experiments; $15 \mathrm{~g}$ of agar (Difco) per liter of LB was used for E. coli. If required, chloramphenicol was added at concentrations of 25 $\mu \mathrm{g} / \mathrm{mL}$ for E. coli DH5 $\alpha, 15 \mu \mathrm{g} / \mathrm{mL}$ for E. coli TG90, and $7 \mu \mathrm{g} /$ $\mathrm{mL}$ for B. smithii.

Genomic DNA Isolation, Transformations, Colony PCR, Sequencing, and Phenotypic Verification. Genomic 
DNA from B. smithii strains was isolated using the MasterPure Gram positive DNA purification kit (Epicenter). Heat shock transformation of E. coli strains was performed according to the supplier's protocol. Transformation of B. smithii strains was performed as described previously. ${ }^{15}$ Plasmids for transforming $B$. smithii were extracted from E. coli via maxiprep isolation (Genomed Jetstar 2.0). For transformation of B. smithii strains, $1 \mu \mathrm{g}$ DNA was used unless it is stated otherwise in the plasmid construction sections.

Potential B. smithii ET138 $\Delta l d h L \Delta s i g F \Delta p y r F$ colonies were randomly selected and subjected to colony PCR using the InstaGene Matrix (Bio-Rad), Taq DNA polymerase (NEB), and genome-specific primers BG6420 and BG6421. Potential $B$. smithii ET138 $\Delta l d h L \Delta s i g F \Delta h s d R$ and B. smithii ET138 $\Delta$ sigF $\Delta h s d R$ ldhL knock-in colonies were randomly selected and subjected to colony PCR using the Phire Plant direct PCR kit (ThermoFisher Scientific) and genome-specific primers BG7881, BG7882 and BG8142, BG8143, respectively. Purification of PCR products was performed using the Zymoclean gel DNA recovery kit, after running them on $0.8 \%$ agarose gels. The DNA fragments were subsequently sent for sequencing to GATC Biotech. The DNA fragments from the potential B. smithii ET138 $\Delta l d h L \Delta s i g F \Delta h s d R$ colonies were subjected to EcoRV (NEB) restriction digestion. To evaluate the 5-FOA sensitivity and uracil auxotrophy of $B$. smithii ET138 $\Delta$ ldhL $\Delta s i g F \Delta p y r F$ sequence confirmed strains, cells were plated on TVMY medium with $30 \mathrm{~g} / \mathrm{L}$ agar and the following additions: (a) $2 \mathrm{~g} / \mathrm{L}$ 5-FOA and $50 \mathrm{mg} / \mathrm{L}$ uracil, (b) 2 g/L 5-FOA and no uracil, or (c) no 5-FOA and no uracil. To evaluate lactate production from B. smithii ET138 $\Delta s i g F \Delta h s d R$ ldhL knock-in cultures, sequence verified cells were grown overnight in TVMY medium containing $10 \mathrm{~g} / \mathrm{L}$ glucose and subsequently transferred to the same medium and grown for 24 $\mathrm{h}$, after which L-lactate specific measurements were performed using MegaZyme K-LATE kit.

Plasmid Construction. Plasmids and primers used in this study are shown in Tables S2 and S3. Q5 polymerase (NEB) was used for all PCR reactions for cloning purposes. NEB T4 ligase was used for assembling the pWUR_lacZ, pWUR_Cas9nt, pWUR_Cas9nt_hr, pWUR_Cas9sp1, pWUR_Cas9sp1_hr, pWŪR_Cas9sp2, and pWUR_Cas9sp3 vectors. The NEBuilder HiFi DNA assembly master mix was used for assembling the pWUR_Cas9spR_hr, pWUR_Cas9spKI_hr1, and pWUR_Cas9spKI_hr2 constructs. All restriction enzymes were obtained from NEB. Purification of PCR products was performed after running them on a $0.8 \%$ agarose gel using the Zymoclean gel DNA recovery kit.

To test the $\mathrm{P}_{x y n A}$ promoter, a DNA fragment composed of $\mathrm{P}_{x y n A}$ and the lacZ gene was synthesized by GeneArt and inserted into pNW33n using digestion with BspHI and KpnI and subsequent ligation and cloning into E. coli DH5 $\alpha$, creating plasmid pWUR_lacZ. The $\mathrm{P}_{x y n A}$ sequence was used exactly as originally described, ${ }^{47}$ using the sequence until the start codon of the corresponding gene in the original host.

For the construction of the basic, modular pWUR_Cas9nt construct, a synthetic gene string was synthesized by $\overline{\text { GeneArt }}$ containing the elements depicted in Figure $1 \mathrm{~B}$ except the $\mathrm{P}_{x y n A}$ promoter. $\mathrm{P}_{x y n A}$ was amplified from $\mathrm{pWUR}$ lacZ using primers BG6538 and BG6541. Primer BG6541 replaces the final $6 \mathrm{bp}$ of $\mathrm{P}_{x y n A}$ with an $\mathrm{XbaI}$ site, changing the final -1 to -6 sequence from GTAAGA to TCTAGA and keeping the total length the same as that in the original promoter. Primer BG6538 adds a BspHI site to the start of $\mathrm{P}_{x y n}$. The entire synthesized spCas9 module without a promoter for spCas9 was amplified using primers BG6542 and BG6543, keeping the XbaI and HindIII sites already present in the module. Subsequently, vector pNW33n was digested with BspHI and HindIII, the $\mathrm{P}_{x y n A}$ PCR product was digested with $\mathrm{XbaI}$ and $\mathrm{BspHI}$, and the spCas9 module PCR product was digested with $\mathrm{XbaI}$ and HindIII. The three elements were ligated in a three-point ligation and cloned into E. coli TG90. The plasmid was extracted, and the correct sequence was verified by sequencing, creating plasmid pWUR_Cas9nt (Figure 2B). For transformation of this construct to $B$. smithii strains, $0.1 \mu \mathrm{g}$ of DNA was used rather than the standard $1 \mu \mathrm{g}$ in order to more precisely determine the transformation efficiencies together with the targeting constructs described in the next section. The resulting CFUs were around 3000 and 200 per $\mu$ g of DNA for the $\Delta l d h L \Delta s i g F$ and wild-type strains, respectively. Control transformations with empty vector pNW33n yielded CFUs of 10000 and 1800, respectively.

To insert the three different targeting spacers into pWUR_Cas9nt (which contains a nontargeting spacer), three sets of oligos were annealed to create the three spacers, after which the annealed spacers were inserted into the construct as follows. Oligo sets were BG6017 and BG6021 for spacer 1, BG6018 and BG6022 for spacer 2, BG6019 and BG6023 for spacer 3. Each set was annealed by adding $5 \mu \mathrm{L}$ of $10 \mathrm{mM}$ oligo sets together with $10 \mu \mathrm{L}$ of NEB buffer 2.1 and $74 \mu \mathrm{L}$ of MQ water. Mixtures were heated to $94{ }^{\circ} \mathrm{C}$ for $5 \mathrm{~min}$ and gradually cooled to $37{ }^{\circ} \mathrm{C}$ at $0.03{ }^{\circ} \mathrm{C} / \mathrm{s}$ using a PCR machine. Annealed oligos and plasmid pWUR_Cas9nt were digested with BspEI and BsmBI (NEB). First, BspEI digestion was performed at 37 ${ }^{\circ} \mathrm{C}$ for $15 \mathrm{~min}$, after which $\mathrm{BsmBI}$ was added and the mixture was further incubated at $55{ }^{\circ} \mathrm{C}$ for $15 \mathrm{~min}$. After gel purification of the digested products, ligation was performed using NEB T4 ligase, and mixtures were transformed into E. coli TG90. All constructs were verified by sequencing, and all were correct except spacer 2, which was missing 7 nt from $\mathrm{P}_{\text {pta }}$ that drives spacer expression (Figure S2). Constructs were named pWUR_Cas9sp1 to pWUR_Cas9sp3 according to their corresponding spacer. For transformation of this construct into B. smithii strains, $0.1 \mu \mathrm{g}$ of DNA was used rather than the standard $1 \mu \mathrm{g}$ in order to more precisely determine the transformation efficiencies. The resulting CFUs were 7003300 and $9-300$ per $\mu \mathrm{g}$ of DNA for the $\Delta l d h L \Delta s i g F$ and wildtype strains, respectively. Control transformations with empty vector pNW33n yielded CFUs of 10000 and 1800, respectively.

To insert the pyrF flanks into the pWUR_Cas9nt and pWUR_Cas9sp1constructs, the already fused $p y r \bar{F}$ flanks were amplified from a previous plasmid in which the flanks were added as follows: flanks were cloned from genomic DNA of ET 138 using primers BG 5798, BG5799 (upstream, 958 bp) and BG580, BG5801 (downstream, 979 bp), introducing SalI and $\mathrm{XbaI}$ restriction sites. The flanks were fused in an overlap extension PCR using primers BG5798 and BG5801, making use of the complementary overhangs in primers BG5799 and BG5800. Subsequently, the flanks and pNW33n were digested with SalI and XbaI, ligated, and transformed into E. coli DH5 $\alpha$. To amplify the flanks for insertion into spCas9-editing plasmids, primers BG6850 and BG6849 were used, which both introduce a BspHI site. The pWUR_Cas9nt and pWUR_Cas9sp1 plasmids and the amplified pyrF flanks were digested with BspHI, followed by alkaline phosphatase treatment of the vectors (Thermo Scientific), ligated, and 
transformed into E. coli TG90. Since only one restriction site was used, the flanks could have been inserted in both orientations. For both constructs, multiple colonies were verified by sequencing, and for all constructs, the same flank orientation was selected and used for future experiments, namely, the downstream flank on the $\mathrm{P}_{x y n A}$ side. The resulting plasmids were named pWUR_Cas9nt_hr and pWUR_Cas9sp1_hr. Transformation of these constructs into B. smithii $\Delta l d h L \overline{\Delta s i g F}$ using $0.1 \mu \mathrm{g}$ of DNA like that for the nonflanked versions did not yield any colonies, most likely because there is a RM recognition site present in the flanking regions (data not shown). Transformations performed using 5-8 $\mu \mathrm{g}$ of DNA resulted in CFUs of around 10 per $\mu \mathrm{g}$ of DNA (compared to around 700-3300 for the nonflanked versions and 10000 for control transformations with empty vector $\mathrm{pNW} 33 \mathrm{n}$ ).

A four-fragment NEBuilder HiFi DNA assembly was designed and executed for the construction of the $h s d R$ modifying plasmid pWUR_Cas9spR_hr. The backbone of the vector was PCR amplified from pWUR_Cas9sp1 using primers BG7836 and BG7837. The HR fragment upstream of the targeted site in the $h s d R$ gene was PCR amplified from the $B$. smithii ET 138 genome using primers BG7838 and BG7839. The HR fragment downstream of the targeted site in the $h s d R$ gene was PCR amplified from the B. smithii ET 138 genome using primers BG7840 and BG7841. The cas $9_{s p}$ and sgRNA containing fragment was PCR amplified from the pWUR_Cas9sp1 vector using primers BG7842 and BG7843.

Two 4-fragment NEBuilder HiFi DNA assemblies were designed and executed for the construction of the $l d h L$ restoration plasmids pWUR_Cas9spKI_hrl and pWUR_Cas9spKI hr2. The backbone of both vectors was PCR amplified from the pWUR Cas9sp1 vector using primers BG8134 and BG7837. The HR fragment upstream of and including the $l d h L$ gene was PCR amplified from the B. smithii ET 138 genome using primers BG8135 and BG8137 for the pWUR_Cas9spKI_hr1 vector and primers BG8135 and BG8136 for the pWUR_Cas9spKI_hr2 vector. The HR fragment downstream of the $l d h L$ gene was PCR amplified from the B. smithii ET 138 genome using primers BG8138 and BG8139 for the pWUR_Cas9spKI_hrl vector and primers BG8138 and BG8140 for the pWŪR_Cas9spKI_hr2 vector. The cas $9_{s p}$ and sgRNA containing fragment of both vectors was PCR amplified from the pWUR_Cas9sp1 vector using primers BG8141 and BG7842.

RNA Isolation and rt-PCR. RNA isolation was performed by the phenol extraction based on van Hijum et al. ${ }^{48}$ Overnight $10 \mathrm{~mL}$ cultures were centrifuged at $4{ }^{\circ} \mathrm{C}$ and $4816 \mathrm{~g}$ for $15 \mathrm{~min}$ and immediately used for RNA isolation. After removal of the medium, cells were resuspended in $0.5 \mathrm{~mL}$ of ice-cold TE buffer ( $\mathrm{pH}$ 8.0) and kept on ice. All samples were divided into two 2 $\mathrm{mL}$ screw-capped tubes containing $0.5 \mathrm{~g}$ of zirconium beads, 30 $\mu \mathrm{L}$ of $10 \%$ SDS, $30 \mu \mathrm{L}$ of $3 \mathrm{M}$ sodium acetate ( $\mathrm{pH}$ 5.2), and $500 \mu \mathrm{L}$ of Roti-Phenol (pH 4.5-5.0, Carl Roth GmbH). Cells were disrupted using a FastPrep-24 apparatus (MP Biomedicals) at $5500 \mathrm{rpm}$ for $45 \mathrm{~s}$ and centrifuged at $4{ }^{\circ} \mathrm{C}$ and 10000 rpm for $5 \mathrm{~min} .400 \mu \mathrm{L}$ of the water phase from each tube was transferred to a new tube, to which $400 \mu \mathrm{L}$ of chloroformisoamyl alcohol (Carl Roth $\mathrm{GmbH}$ ) was added, after which samples were centrifuged at $4{ }^{\circ} \mathrm{C}$ and $18400 \mathrm{~g}$ for $3 \mathrm{~min} .300$ $\mu \mathrm{L}$ of the aqueous phase was transferred to a new tube and mixed with $300 \mu \mathrm{L}$ of the lysis buffer from the high pure RNA isolation kit (Roche). Subsequently, the rest of the procedure from this kit was performed according to the manufacturer's protocol, except for the DNase incubation step, which was performed for $45 \mathrm{~min}$. Integrity and concentration of the isolated RNA were checked on a NanoDrop 1000.

rt-PCR was performed using SuperScript III reverse transcriptase kit (Invitrogen) according to the manufacturer's protocol. For synthesis of the first-strand cDNA, $2 \mu \mathrm{g}$ of RNA and $200 \mathrm{ng}$ of random primers were used. After cDNA synthesis, the products were used as a template for PCR using spCas9-specific forward and reverse primers BG6237 and BG6232, resulting in a 255 bp product. Products were visualized on a $2 \%$ agarose gel that had been run for $20 \mathrm{~min}$.

\section{ASSOCIATED CONTENT}

\section{S Supporting Information}

The Supporting Information is available free of charge on the ACS Publications website at DOI: 10.1021/acssynbio.6b00339.

Strains used in this study (Table S1); plasmids used in this study (Table S2); primers used in this study (Table S3); results of the enzymatic assay test for L-lactate production (Table S4); lacZ expression controlled by $\mathrm{P}_{x y n A}$ in ET $138 \Delta$ ldhL $\Delta$ sigF grown in TVMY medium containing different carbon sources (Figure S1); sequencing results of the $\mathrm{P}_{p t a}$ from pWUR_Cas9sp2 (Figure S2); $\mathrm{OD}_{600}$ measurements from the ET 138 $\Delta$ sigF $\Delta l d h L$ spCas9 targeting experiment (Figure S3); $\mathrm{OD}_{600}$ measurements from the 7-day long pyrF deletion culturing process (Figure S4); phenotypic evaluation of 5-FOA sensitivity and uracil auxotrophy of wild-type and mutant ET 138 pyrF (Figure S5); and agarose gel electrophoresis showing the resulting products from colony PCR on the colonies from the 3-day long $l d h L$ knock-in culturing processes in LB2 medium (Figure S6) (PDF)

\section{AUTHOR INFORMATION}

\section{Corresponding Author}

*E-mail: richard.vankranenburg@wur.nl. ORCID

Richard van Kranenburg: 0000-0001-5856-1546

\section{Present Address}

"The Novo Nordisk Foundation Center for Biosustainability, Technical University of Denmark, Kemitorvet B220, 2800 Kgs. Lyngby, Denmark (E.F.B.).

\section{Author Contributions}

${ }^{\S}$ I.M. and E.F.B. contributed equally to this work.

Notes

The authors declare no competing financial interest.

\section{ACKNOWLEDGMENTS}

The authors thank Dr. Ben Reeves for the kind donation of the pG2K vector and Prof. Dr. Oscar Kuipers for kindly providing E. coli TG90. This work was supported by the Dutch Technology Foundation STW, which is part of The Netherlands Organization for Scientific Research (NWO) and which is partly funded by the Ministry of Economic Affairs.

\section{REFERENCES}

(1) Bosma, E. F., van der Oost, J., de Vos, W. M., and van Kranenburg, R. (2013) Sustainable production of bio-based chemicals by extremophiles. Curr. Biotechnol. 2, 360-379. 
(2) Lin, L., and $\mathrm{Xu}, \mathrm{J}$. (2013) Dissecting and engineering metabolic and regulatory networks of thermophilic bacteria for biofuel production. Biotechnol. Adv. 31, 827-837.

(3) Olson, D. G., Sparling, R., and Lynd, L. R. (2015) Ethanol production by engineered thermophiles. Curr. Opin. Biotechnol. 33, 130-141.

(4) Taylor, M. P., Eley, K. L., Martin, S., Tuffin, M. I., Burton, S. G., and Cowan, D. A. (2009) Thermophilic ethanologenesis: future prospects for second-generation bioethanol production. Trends Biotechnol. 27, 398-405.

(5) Kambam, P. K. R, and Henson, M. A. (2010) Engineering bacterial processes for cellulosic ethanol production. Biofuels 1, 729743.

(6) Ma, K., Maeda, T., You, H., and Shirai, Y. (2014) Open fermentative production of 1-lactic acid with high optical purity by thermophilic Bacillus coagulans using excess sludge as nutrient. Bioresour. Technol. 151, 28-35.

(7) Beckner, M., Ivey, M. L., and Phister, T. G. (2011) Microbial contamination of fuel ethanol fermentations. Lett. Appl. Microbiol. 53, 387-394.

(8) Qin, J., Zhao, B., Wang, X., Wang, L., Yu, B., Ma, Y., Ma, C., Tang, H., Sun, J., and $\mathrm{Xu}, \mathrm{P}$. (2009) Non-sterilized fermentative production of polymer-grade L-lactic acid by a newly isolated thermophilic strain Bacillus sp. 2-6. PLoS One 4, e4359.

(9) Abdel-Banat, B. M., Hoshida, H., Ano, A., Nonklang, S., and Akada, R. (2010) High-temperature fermentation: how can processes for ethanol production at high temperatures become superior to the traditional process using mesophilic yeast? Appl. Microbiol. Biotechnol. $85,861-867$.

(10) Ouyang, J., Ma, R., Zheng, Z., Cai, C., Zhang, M., and Jiang, T. (2013) Open fermentative production of L-lactic acid by Bacillus sp. strain NL01 using lignocellulosic hydrolyzates as low-cost raw material. Bioresour. Technol. 135, 475-480.

(11) Ye, L., Zhou, X., Hudari, M. S., Li, Z., and Wu, J. C. (2013) Highly efficient production of L-lactic acid from xylose by newly isolated Bacillus coagulans C106. Bioresour. Technol. 132, 38-44.

(12) Ou, M., Mohammed, N., Ingram, L., and Shanmugam, K. (2009) Thermophilic Bacillus coagulans requires less cellulases for simultaneous saccharification and fermentation of cellulose to products than mesophilic microbial biocatalysts. Appl. Biochem. Biotechnol. 155, $76-82$.

(13) Bhalla, A., Bansal, N., Kumar, S., Bischoff, K. M., and Sani, R. K. (2013) Improved lignocellulose conversion to biofuels with thermophilic bacteria and thermostable enzymes. Bioresour. Technol. $128,751-759$.

(14) Taylor, M. P., van Zyl, L., Tuffin, I. M., Leak, D. J., and Cowan, D. A. (2011) Genetic tool development underpins recent advances in thermophilic whole-cell biocatalysts. Microb. Biotechnol. 4, 438-448.

(15) Bosma, E. F., van de Weijer, A. H. P., van der Vlist, L., de Vos, W. M., van der Oost, J., and van Kranenburg, R. (2015) Establishment of markerless gene deletion tools in thermophilic Bacillus smithii and construction of multiple mutant strains. Microb. Cell Fact. 14, 99.

(16) Bosma, E. F., van de Weijer, A. H. P., Daas, M. J. A., van der Oost, J., de Vos, W. M., and van Kranenburg, R. (2015) Isolation and screening of thermophilic Bacilli from compost for electrotransformation and fermentation: characterization of Bacillus smithii ET 138 as a new biocatalyst. Appl. Environ. Microbiol. 81, 1874-1883.

(17) Nakamura, L. K., Blumenstock, I., and Claus, D. (1988) Taxonomic study of Bacillus coagulans Hammer 1915 with a proposal for Bacillus smithii sp. nov. Int. J. Syst. Bacteriol. 38, 63-73.

(18) Van Spanning, R. J. M., Wansell, C. W., Reijnders, W. N. M., Harms, N., Ras, J., Oltmann, L. F., and Stouthamer, A. H. (1991) A method for introduction of unmarked mutations in the genome of Paracoccus denitrificans: Construction of strains with multiple mutations in the genes encoding periplasmic cytochromes c550, c(551i), and c(553i). J. Bacteriol. 173, 6962-6970.

(19) Wang, Q., Ingram, L. O., and Shanmugam, K. T. (2011) Evolution of D-lactate dehydrogenase activity from glycerol dehydro- genase and its utility for D-lactate production from lignocellulose. Proc. Natl. Acad. Sci. U. S. A. 108, 18920-18925.

(20) Wang, Q., Chen, T., Zhao, X., and Chamu, J. (2012) Metabolic engineering of thermophilic Bacillus licheniformis for chiral pure D-2,3butanediol production. Biotechnol. Bioeng. 109, 1610-1621.

(21) Barrangou, R., Fremaux, C., Deveau, H., Richards, M., Boyaval, P., Moineau, S., Romero, D. A., and Horvath, P. (2007) CRISPR provides acquired resistance against viruses in prokaryotes. Science 315, $1709-1712$.

(22) Jinek, M., Chylinski, K., Fonfara, I., Hauer, M., Doudna, J. A., and Charpentier, E. (2012) A programmable dual-RNA-guided DNA endonuclease in adaptive bacterial immunity. Science 337, 816-821.

(23) Jinek, M., East, A., Cheng, A., Lin, S., Ma, E., and Doudna, J. (2013) RNA-programmed genome editing in human cells. eLife 2, e00471.

(24) Mali, P., Yang, L., Esvelt, K. M., Aach, J., Guell, M., DiCarlo, J. E., Norville, J. E., and Church, G. M. (2013) RNA-guided human genome engineering via Cas9. Science 339, 823-826.

(25) Cong, L., Ran, F. A., Cox, D., Lin, S., Barretto, R., Habib, N., Hsu, P. D., Wu, X., Jiang, W., Marraffini, L. A., and Zhang, F. (2013) Multiplex genome engineering using CRISPR/Cas systems. Science 339, 819-823.

(26) Kim, S., Kim, D., Cho, S. W., Kim, J., and Kim, J.-S. (2014) Highly efficient RNA-guided genome editing in human cells via delivery of purified Cas9 ribonucleoproteins. Genome Res. 24, 10121019.

(27) Komor, A. C., Badran, A. H., and Liu, D. R. (2017) CRISPRbased technologies for the manipulation of eukaryotic genomes. Cell 168, 20-36.

(28) Puchta, H. (2017) Applying CRISPR/Cas for genome engineering in plants: the best is yet to come. Curr. Opin. Plant Biol. $36,1-8$.

(29) Xu, J., Ren, X., Sun, J., Wang, X., Qiao, H. H., Xu, B. W., Liu, L. P., and Ni, J. Q. (2015) A Toolkit of CRISPR-Based Genome Editing Systems in Drosophila. J. Genet. Genomics 42, 141-149.

(30) Bowater, R., and Doherty, A. J. (2006) Making ends meet: repairing breaks in bacterial DNA by non-homologous end-joining. PLoS Genet. 2, e8.

(31) Bosma, E. F., Koehorst, J. J., van Hijum, S. A., Renckens, B., Vriesendorp, B., van de Weijer, A. H., Schaap, P. J., de Vos, W. M., van der Oost, J., and van Kranenburg, R. (2016) Complete genome sequence of thermophilic Bacillus smithii type strain DSM 4216(T). Stand. Genomic Sci. 11, 52.

(32) Shuman, S., and Glickman, M. S. (2007) Bacterial DNA repair by non-homologous end joining. Nat. Rev. Microbiol. 5, 852-861.

(33) Jiang, W., Bikard, D., Cox, D., Zhang, F., and Marraffini, L. A. (2013) RNA-guided editing of bacterial genomes using CRISPR-Cas systems. Nat. Biotechnol. 31, 233-239.

(34) Barrangou, R., and van Pijkeren, J. P. (2016) Exploiting CRISPR-Cas immune systems for genome editing in bacteria. Curr. Opin. Biotechnol. 37, 61-68.

(35) Mougiakos, I., Bosma, E. F., de Vos, W. M., van Kranenburg, R., and van der Oost, J. (2016) Next generation prokaryotic engineering: The CRISPR-Cas toolkit. Trends Biotechnol. 34, 575-587.

(36) Xu, T., Li, Y., Shi, Z., Hemme, C. L., Li, Y., Zhu, Y., Van Nostrand, J. D., He, Z., and Zhou, J. (2015) Efficient genome editing in Clostridium cellulolyticum via CRISPR-Cas9 nickase. Appl. Environ. Microbiol. 81, 4423-4431.

(37) Huang, H., Zheng, G., Jiang, W., Hu, H., and Lu, Y. (2015) One-step high-efficiency CRISPR/Cas9-mediated genome editing in Streptomyces. Acta Biochim. Biophys. Sin. 47, 231-243.

(38) Huang, H., Chai, C., Li, N., Rowe, P., Minton, N. P., Yang, S., Jiang, W., and Gu, Y. (2016) CRISPR/Cas9-based efficient genome editing in Clostridium ljungdahlii, an autotrophic gas-fermenting bacterium. ACS Synth. Biol. 5, 1355-1361.

(39) Li, Q., Chen, J., Minton, N. P., Zhang, Y., Wen, Z., Liu, J., Yang, H., Zeng, Z., Ren, X., Yang, J., Gu, Y., Jiang, W., Jiang, Y., and Yang, S. (2016) CRISPR-based genome editing and expression control systems 
in Clostridium acetobutylicum and Clostridium beijerinckii. Biotechnol. J. 11, 961-972.

(40) Wang, Y., Zhang, Z. T., Seo, S. O., Choi, K., Lu, T., Jin, Y. S., and Blaschek, H. P. (2015) Markerless chromosomal gene deletion in Clostridium beijerinckii using CRISPR/Cas9 system. J. Biotechnol. 200, $1-5$.

(41) Li, Y., Lin, Z., Huang, C., Zhang, Y., Wang, Z., Tang, Y.-j., Chen, T., and Zhao, X. (2015) Metabolic engineering of Escherichia coli using CRISPR-Cas9 meditated genome editing. Metab. Eng. 31, 13-21.

(42) Wang, Y., Zhang, Z. T., Seo, S. O., Lynn, P., Lu, T., Jin, Y. S., and Blaschek, H. P. (2016) Bacterial genome editing with CRISPRCas9: deletion, integration, single nucleotide modification, and desirable "clean" mutant selection in Clostridium beijerinckii as an example. ACS Synth. Biol. 5, 721-732.

(43) Tong, Y., Charusanti, P., Zhang, L., Weber, T., and Lee, S. Y. (2015) CRISPR-Cas9 based engineering of Actinomycetal genomes. ACS Synth. Biol. 4, 1020-1029.

(44) Jiang, Y., Chen, B., Duan, C., Sun, B., Yang, J., and Yang, S. (2015) Multigene editing in the Escherichia coli genome via the CRISPR-Cas9 system. Appl. Environ. Microbiol. 81, 2506-2514.

(45) Li, Y., Pan, S., Zhang, Y., Ren, M., Feng, M., Peng, N., Chen, L., Liang, Y. X., and She, Q. (2016) Harnessing Type I and Type III CRISPR-Cas systems for genome editing. Nucleic Acids Res. 44, e34.

(46) Zeldes, B. M., Keller, M. W., Loder, A. J., Straub, C. T., Adams, M. W., and Kelly, R. M. (2015) Extremely thermophilic microorganisms as metabolic engineering platforms for production of fuels and industrial chemicals. Front. Microbiol. 6, 1209.

(47) Currie, D., Herring, C., Guss, A., Olson, D., Hogsett, D., and Lynd, L. (2013) Functional heterologous expression of an engineered full length CipA from Clostridium thermocellum. Biotechnol. Biofuels 6, 32.

(48) van Hijum, S. A., de Jong, A., Baerends, R. J., Karsens, H. A., Kramer, N. E., Larsen, R., den Hengst, C. D., Albers, C. J., Kok, J., and Kuipers, O. P. (2005) A generally applicable validation scheme for the assessment of factors involved in reproducibility and quality of DNAmicroarray data. BMC Genomics 6, 77.

(49) Kovács, Á. T., van Hartskamp, M., Kuipers, O. P., and van Kranenburg, R. (2010) Genetic tool development for a new host for biotechnology, the thermotolerant bacterium Bacillus coagulans. Appl. Environ. Microbiol. 76, 4085-4088.

(50) Tripathi, S. A., Olson, D. G., Argyros, D. A., Miller, B. B., Barrett, T. F., Murphy, D. M., McCool, J. D., Warner, A. K., Rajgarhia, V. B., Lynd, L. R., Hogsett, D. A., and Caiazza, N. C. (2010) Development of pyrF-based genetic system for targeted gene deletion in Clostridium thermocellum and creation of a pta mutant. Appl. Environ. Microbiol. 76, 6591-6599.

(51) Kita, A., Iwasaki, Y., Yano, S., Nakashimada, Y., Hoshino, T., and Murakami, K. (2013) Isolation of thermophilic acetogens and transformation of them with the pyrF and kanr genes. Biosci., Biotechnol., Biochem. 77, 301-306.

(52) Chung, D., Farkas, J., Huddleston, J. R., Olivar, E., and Westpheling, J. (2012) Methylation by a unique alpha-class N4cytosine methyltransferase is required for DNA transformation of Caldicellulosiruptor bescii DSM6725. PLoS One 7, e43844.

(53) Biswas, I., Gruss, A., Ehrlich, S. D., and Maguin, E. (1993) Highefficiency gene inactivation and replacement system for gram-positive bacteria. J. Bacteriol. 175, 3628-3635.

(54) Morel-Deville, F., and Ehrlich, S. D. (1996) Theta-type DNA replication stimulates homologous recombination in the Bacillus subtilis chromosome. Mol. Microbiol. 19, 587-598.

(55) Reeve, B., Martinez-Klimova, E., de Jonghe, J., Leak, D. J., and Ellis, T. (2016) The Geobacillus plasmid set: a modular toolkit for thermophile engineering. ACS Synth. Biol. 5, 1342-1347.

(56) Cui, L., and Bikard, D. (2016) Consequences of Cas9 cleavage in the chromosome of Escherichia coli. Nucleic Acids Res. 44, 42434251 .

(57) Oh, J.-H., and van Pijkeren, J.-P. (2014) CRISPR-Cas9-assisted recombineering in Lactobacillus reuteri. Nucleic Acids Res. 42, e131.
(58) Ronda, C., Pedersen, L. E., Sommer, M. O., and Nielsen, A. T. (2016) CRMAGE: CRISPR optimized MAGE recombineering. Sci. Rep. 6, 19452.

(59) Kingsford, C. L., Ayanbule, K., and Salzberg, S. L. (2007) Rapid, accurate, computational discovery of Rho-independent transcription terminators illuminates their relationship to DNA uptake. Genome Biol. 8 , R22. 